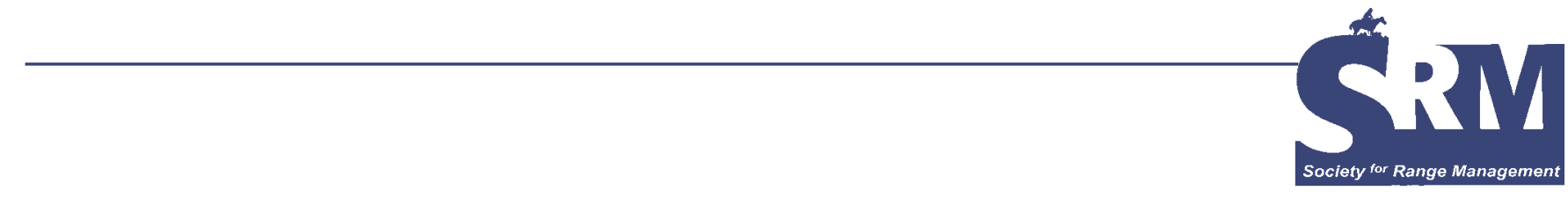

\title{
Speaking With People in Our Profession
}

\section{An Interview with Dr David D. Briske}

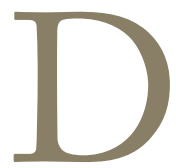

avid Briske is a Professor of Rangeland Ecology in the Department of Ecosystem Science and Management at Texas A\&M University. A native of North Dakota, David completed his undergraduate degree in Botany from North Dakota State University in 1973, and his $\mathrm{PhD}$ in Range Science from Colorado State University in 1978. He joined the faculty at Texas A\&M in 1978, and has actively pursued his research interests in physiological plant ecology, global change biology, and grassland ecology, among other topics, over the past $30 \mathrm{yr}$. His list of refereed publications is extensive, and includes some of the most significant papers in the profession in recent years. In 2008, the Society for Range Management awarded Dr Briske its highest recognition for accomplishments in research-the W. R. Chapline Research Award. He is an active educator, and many of his former graduate students are now also prominent scientists and academics. David has been a member of the SRM since 1973, and recently agreed to assume duties as Editorin-Chief of Rangeland Ecology and Management (REM) beginning in 2008. He managed to take a few moments out of his busy schedule to answer a few questions about the role of science and publishing in a field discipline devoted to management of natural resources.

\section{Working to Improve the Quality of Science-Based Information \\ Question: Why did you choose to accept the invitation to serve as REM editor in addition to all of your other duties as a professor?}

Answer: It was partially based on the realization that it was time in my career to take on greater leadership roles. The editor of REM represents a tremendous opportunity to support the rangeland profession, the Society for Range Management, and stewardship of global rangelands. In addition, I have been impressed with the changes that have occurred in recent years both in the Society and with $R E M$. I felt an obligation to support these activities and to contribute to the momentum that has been developed. I worked closely with Keith Owens, the former editor of $R E M$, during the past $3 \mathrm{yr}$ so I saw the improvements that he had implemented and the new possibilities that had been created by these changes. I wanted to become a part of this exciting period of transformation.

\section{What are some of the new possibilities that you envision for REM?}

My vision is for REM to become the clearinghouse for all science-based information for global rangelands, i.e., the go-to source for all rangeland issues. The selection of a major academic publisher, Allen Press, to publish and distribute $R E M$, both in electronic and print form, has created several far-reaching possibilities for the Journal. Rangelands comprise $40 \%$ of the earth's land area and provide numerous ecological services to humankind. REM needs to more aggressively and creatively occupy this important academic niche.

\section{Do you see an increasingly international content for the journal?}

Yes, there has been a substantial increase in international submissions as well as greater access of REM content by international authors. This represents the involvement of scientists who had not previously considered $R E M$ as an outlet for their work or recognized its content. I think that greater international involvement is largely a result of 


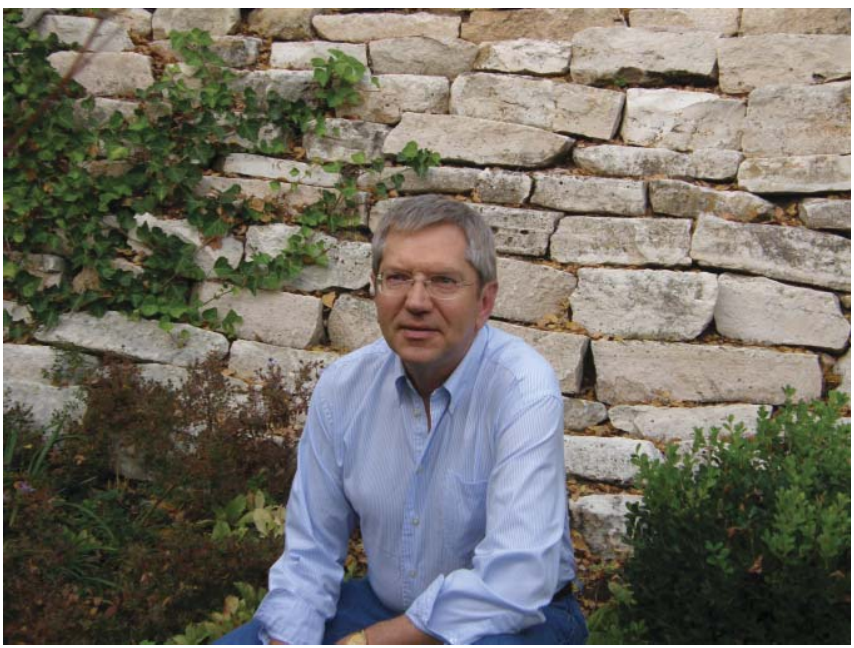

David Briske at ease in a quiet moment.

aggressive electronic distribution of REM by Allen Press. In addition, the former editor has increased the proportion of international scientists on the editorial board to promote international recognition. The wise stewardship of rangelands is a global issue so I anticipate that this trend of increasing international involvement will continue.

\section{So, in a world that is increasingly accessing} information wirelessly, instantly, and in audio and video formats, what is the future of a print journal?

The role of print format is rapidly being replaced by on-line delivery for academic journals. Subscribers of many ecological journals currently receive only electronic content, even though print material remains available. The publisher of SRM journals, Allen Press, recognizes this trend and is making efforts to adjust. For example, REM will begin to publish accepted papers on-line on the REM Web site well ahead of print publication in 2008. I envision this to become the major form of content delivery in the near future.

There are, though, other obstacles that need to be addressed. In the 2 November 2007 issue of Science, maybe the world's premier scientific journal, all research articles have a one-page illustrated summary provided for readers. This experiment seems to be an effort to address two classic problems: 1) people are less willing to read articles in their entirety and 2) scientists are not always the best writers and communicators of their science. Are these also problems facing our journal and its readership?

Yes, I entirely agree that we are overwhelmed with content in the information age. A partial solution is to establish $R E M$ as the go-to source for rangeland issues so that it will be among the initial sites selected when setting priorities for information retrieval. The mission of REM is to effectively communicate science-based information and scientists and researchers are the best sources to provide this information. However, we can provide papers written in various styles that address a variety of important topics. We plan to promote the publication of forum papers to address high-profile rangeland issues and policies. Hopefully, these papers will be highly readable and highly read.

\section{Does this imply that you will move our journal toward an additional emphasis beyond reductionist science?}

Absolutely. The rangeland profession is currently engaged in a paradigm where we are attempting to manage ecosystems and set policies based on the maintenance of ecosystem resilience. This requires a very different way of approaching and conducting science in our profession. The previous perspective has contributed to the knowledge base of our profession, but we need to look beyond this narrow focus on small plots and highly controlled experimental designs so that we can more effectively address resilience-based management. In other words, we can't wait for reductionism to provide all of the information necessary to manage complex ecosystems.

\section{How then do you react to the often-stated comment} that rangeland management is not a science?

Certainly, rangeland management is often experiencebased, but we must constantly attempt to develop management and policy recommendations that are science-based. Although important, observation and experience are insufficient foundations for our profession. Our profession must be grounded on information derived from the scientific method. A major challenge currently confronting our profession is to differentiate between science- and faith-based management recommendations and policies.

In recent years there have been a number of positive changes that have occurred in our profession. The manner in which federal rangeland managers have recently welcomed academic involvement and the inclusion of science-based information has been especially gratifying. A recent example is the manner in which the Rangeland Conservation Effects Assessment Program directed by the Natural Resources Conservation Service has deliberately partnered with the scientific community. I think that much of this change in our professional culture was driven by the shift towards state-and-transition models as a way to describe ecological dynamics on rangelands. This was a very traumatic change for many in the profession, and it remains to be difficult for some, but it has renewed a science-based culture in the profession.

\section{What do you envision to be the long-term role of REM for the rangeland profession?}

The rangeland profession is becoming increasingly fragmented with fewer stand-alone academic rangeland programs and a decreasing number of students majoring in 
range science. However, this does not necessarily imply that the number of professionals capable of contributing to rangeland issues is decreasing, but only that they are more diverse than they have been in the past. I envision $R E M$ to be the thread that binds rangeland professionals into an organized entity on a global scale.

How do you anticipate that your research program will change now that you are editor of REM?

I continue to be energized by academic research and to my mind it provides the ultimate excitement to an academic career. I plan to continue to emphasize research topics that provide opportunities to increase science-based management by linking ecological theory with management application. In the immediate future, I will continue to conduct research on the topics of rangeland ecosystem assessment and global change issues.
Rumor has it you are a big fan of the movie "Caddyshack." Are there some professional insights we can draw from your allure for this film?

No, not for our profession. If there is any insight provided by this movie's appeal, it's probably related to my impressions of our current political situation. Can you guess who I think that one of the movie's main characters, Rodney Dangerfield, represents?

Interview was by Susan R. McGuire, a pen name used by the author of this article. Her interviews with members of our profession are a regular contribution to Rangelands. All costs of publishing these interviews are sponsored by a research unit of the Agricultural Research Service, the in-house research agency of the United States Dept of Agriculture, whose rangeland scientists are a segment of our Society.

\section{SRM Charter Members}

Editor's note: this is a corrected list of the SRM Charter Members printed in the February 2008 issue of Rangelands. If a name is not on the list it may be because the member is deceased or his/her membership has expired. We sincerely apologize for any name that was left off the list in February.

E. William Anderson

James R. Brunner

Dwight R. Cable

Howard R. DeLano

John S. Forsman

Robert W. Harris

Harold F. Heady

Walter E. Howard

Robert R. Humphrey

William D. Hurst

George W. Kansky

Paul A. Krause

William Longhurst

Glenn H. Mueller

Gene F. Payne

Rudy J. Pederson

Charles E. Poulton

Laurence E. Riordan

Max E. Robinson

Robert S. Rummell

Harry W. Springfield

Gerald W. Thomas

George T. Turner

Clinton H. Wasser
Lake Oswego, OR

Medford, OR

Eugene, OR

Oregon City, OR

Portland, OR

Milwaukie, OR

La Grande, OR

Davis, CA

Tucson, AZ

Salt Lake City, UT

Langley, WA

Chubbuck, ID

Roseburg, OR

Libby, MT

Bozeman, MT

San Angelo, TX

Peoria, AZ

Mesa, AZ

Orem, UT

Bethesda, MD

Peoria, AZ

Las Cruces, NM

Fort Collins, CO

Lompoc, CA 